\title{
ARTICLE OPEN \\ Comparison of glycopyrronium versus tiotropium on the time to clinically important deteriorations in patients with COPD: a post-hoc analysis of randomized trials
}

\author{
Anthony D'Urzo ${ }^{1}$, Giovanni Bader ${ }^{2}$, Steven Shen ${ }^{2}$, Pankaj Goyal ${ }^{2}$ and Pablo Altman ${ }^{3}$
}

Glycopyrronium is a once-daily, inhaled long-acting muscarinic antagonist (LAMA) demonstrating similar efficacy to inhaled tiotropium in patients with moderate-to-severe COPD; however, the benefit of LAMAs on COPD symptoms has been variable. COPD is a progressive disease in which many patients develop an acute or sustained deterioration. Data on the prevention of clinically important deteriorations (CID) using LAMAs are limited. A pooled analysis was performed on four Phase III trials $(n=2936)$ that compared the efficacy of glycopyrronium $(n=1859)$ with tiotropium $(n=1077)$. The primary endpoint was significant delay and/or reduction in the occurrence of CID. CID was defined as any of the following: $\geq 100 \mathrm{~mL}$ decrease from baseline in pre-dose forced expiratory volume in 1 second $\left(\mathrm{FEV}_{1}\right), \geq 4$ point increase in St George's Respiratory Questionnaire score or a moderate-to-severe COPD exacerbation occurring after the first dose of study medication. A sustained CID was a CID occurring on $\geq 2$ consecutive visits 4 weeks apart or for $\geq 50 \%$ of all available subsequent visits. Baseline characteristics for the overall population were similar. Patients had moderate $(62 \%)$ or severe (38\%) COPD. Mean post-bronchodilator FEV 1 was approximately $55 \%$ predicted, and mean FEV 1 reversibility was 16.7 and $18.6 \%$ in the glycopyrronium and tiotropium groups, respectively. Both glycopyrronium and tiotropium significantly reduced time to CID and sustained CID versus placebo $(p<0.001)$. No statistically significant differences were found between the glycopyrronium and tiotropium treatment groups in time to CID or sustained CID. Glycopyrronium is effective in delaying time to clinically important deteriorations, with similar efficacy to tiotropium.

npj Primary Care Respiratory Medicine (2018)28:18; doi:10.1038/s41533-018-0084-8

\section{INTRODUCTION}

Chronic obstructive pulmonary disease (COPD) is a heterogeneous condition comprising multiple pulmonary and extra-pulmonary manifestations. ${ }^{1,2}$ The disease has a variable natural history and significant heterogeneity exists with respect to clinical presentation, response to therapy, and survival. ${ }^{1-3}$ As a result, there is consensus that spirometry alone does not adequately reflect the complexity of the disease and is an incomplete marker of the severity of symptoms, exercise limitation and health status.,

In recognition of the complexities of COPD, a large number of guideline-based therapies are available that aim to improve symptoms, reduce the frequency and severity of exacerbations, and improve health status and exercise tolerance. ${ }^{5}$ The Global Initiative for Chronic Obstructive Lung Disease (GOLD) 2017 strategy now recommends that COPD management should consider both disease impact (i.e., assessment of symptoms) measured by the COPD Assessment Test (CAT) or modified Medical Research Council (mMRC) dyspnea scale, and exacerbation history. ${ }^{5}$ Guidelines recommend long-acting bronchodilator therapy, including long-acting muscarinic antagonists (LAMAs), as a first choice therapy in all GOLD patient groups. ${ }^{5}$

Glycopyrronium is a once-daily LAMA indicated for the maintenance treatment of patients with COPD. ${ }^{6}$ Phase III trials have shown that glycopyrronium produces rapid and sustained improvements in lung function, symptoms, health status, exercise endurance and exacerbation risk in patients with COPD. ${ }^{7-11}$ Although glycopyrronium has an efficacy and safety profile similar to the widely prescribed LAMA tiotropium bromide, ${ }^{7,9,11,12}$ studies have indicated a faster onset of action and greater bronchodilation with glycopyrronium within the first $4 \mathrm{~h}$ after the first dose on Day 1 of treatment. ${ }^{9}$

COPD clinical trials primarily focus on bronchodilator response using minimal clinically important difference (MCID) to determine improvements in lung function and patient-reported outcomes. ${ }^{13-}$ ${ }_{15}$ Clinically important deterioration (CID) assesses individual deteriorations in lung function, health status and moderate-tosevere exacerbations. ${ }^{15}$

The efficacy and safety of glycopyrronium has been evaluated in a number of randomized controlled trials, primarily in patients with moderate-to-severe COPD. We conducted a post-hoc analysis of four Phase III trials, namely the glycopyrronium bromide in COPD airways (GLOW1, GLOW2, GLOW5) ${ }^{9-11}$ and SHINE studies, ${ }^{7}$ to compare the efficacy of glycopyrronium and tiotropium in patients with COPD in terms of CID delay and/or reduction.

\section{RESULTS}

Study populations and baseline characteristics

A total of 2936 patients were included in this analysis (glycopyrronium $n=1859$; tiotropium $n=1077$ ). Baseline

\footnotetext{
${ }^{1}$ Department of Family and Community Medicine, Faculty of Medicine, University of Toronto, Toronto, Canada; ${ }^{2}$ Novartis Pharma AG, Fabrikstrasse 2, Basel, Switzerland and ${ }^{3}$ Novartis Pharmaceuticals Corporation, East Hanover, NJ, USA

Correspondence: Anthony D'Urzo (tonydurzo@sympatico.ca)
}

Received: 20 September 2017 Revised: 28 March 2018 Accepted: 17 April 2018

Published online: 24 May 2018 
characteristics were similar for the two treatment groups (Table 1). For the overall population, the mean age was 64 years, the majority of patients were male $(74 \%$ and $72 \%$ in the glycopyrronium and tiotropium groups, respectively), and the mean duration of COPD was 6.5 years. Most patients in both treatment groups had either moderate $(62 \%)$ or severe $(38 \%)$ COPD. Although the incidence of cardiac comorbidities was low in the overall population, approximately $25 \%$ of patients had documented hypertension and approximately $6 \%$ of patients had type 2 diabetes mellitus. Overall, there were no meaningful differences between treatment groups for spirometry measurements at baseline (Table 1). Mean post-bronchodilator forced expiratory volume in 1 second $\left(\mathrm{FEV}_{1}\right)$ was approximately $55 \%$ of predicted and mean $\mathrm{FEV}_{1}$ reversibility was $16.7 \%$ and $18.6 \%$ in the glycopyrronium and tiotropium groups, respectively. Few patients had a history of an exacerbation ( $25 \%$ of patients reported a COPD exacerbation within the previous 12 months; Table 1). A risk calculation based on the GOLD strategy was therefore not performed on the overall population as it was considered that the calculation would not be representative of patients with different exacerbation phenotypes.

\section{Efficacy}

First and sustained CID. The proportion of patients who experienced a CID ranged non-significantly from $57.8 \%$ in the tiotropium group to $60.1 \%$ in the glycopyrronium group ( $p=$ 0.4658 ; Table 2). This study showed that there was no significant difference in the number of glycopyrronium patients who experienced a sustained CID compared with those receiving tiotropium (53.6\% versus $50.2 \%, p=0.9765$; Table 2 ). The most frequently experienced individual component of the CID definition was $a \geq 100 \mathrm{~mL}$ decline from baseline in $\mathrm{FEV}_{1}$ across the glycopyrronium (38.5\%) and tiotropium (37.5\%) treatment arms $(p=0.4850)$. This was also true for sustained CIDs, where $28.6 \%$ of glycopyrronium and $27.5 \%$ of tiotropium patients experienced a lung-function-related sustained CID $(p=0.5764)$. There were also no significant differences between the proportion of patients in either treatment group who experienced a St George's Respiratory Questionnaire (SGRQ)-related CID or sustained CID ( $p=$ 0.1658 and $p=0.4702$, respectively), or an exacerbation-related CID or sustained CID ( $p=0.1735$ and $p=0.1735$, respectively) (Table 2). Subgroup analysis demonstrated that the risk of experiencing a CID or sustained CID was not significantly different between the glycopyrronium and tiotropium groups, regardless of gender (male or female), age ( $<65$ or $\geq 65$ years), smoking status (current or ex-smoker), exacerbation history, inhaled corticosteroid (ICS) use (yes or no), baseline SGRQ ( $\leq 25$ or $>25$ ) or Baseline Dyspnea Index (BDI; $\leq 7$ or $>7$ ) score, COPD severity (moderate or severe) or blood eosinophil level $(<300$ or $\geq 300$ cells $/ \mu \mathrm{L})$ ( $p>0.0729$; Figs. 1 and 2 ). Of note, glycopyrronium significantly reduced the risk of both first and sustained CID compared with placebo across all subgroups $(p<0.001)$ (Supplementary Figs. 1 and 2).

Time to first and sustained CID. Neither the time to first CID nor sustained CID in patients receiving glycopyrronium was significantly different compared with tiotropium (HR for CID: 0.96 [95\% $\mathrm{Cl}: 0.87,1.07], p=0.4658$ and HR for sustained CID: 1.00 [95\% Cl: $0.90,1.12], p=0.9765)$. Glycopyrronium $(n=1859)$ significantly reduced time to first CID and sustained CID compared with placebo ( $n=760$ ) (HR: 0.46 [95\% Cl: 0.41, 0.51] and HR: 0.44 [95\% Cl: $0.40,0.49]$, both $p<0.0001$ ) (Fig. 3a, b).

FEV 1 and SGRQ at first and sustained CID. At the time of first CID, there was no difference in mean $\mathrm{FEV}_{1} \pm \mathrm{SD}(1.29 \pm 0.466 \mathrm{~L}$ versus $1.32 \pm 0.501 \mathrm{~L}, p=0.3452)$ or mean $\mathrm{SGRQ} \pm \mathrm{SD}$ score (53.92 \pm 16.87 units versus $57.74 \pm 17.47$ units, $p=0.3903$ ) in patients who had
Table 1. Baseline characteristics in the overall population

\begin{tabular}{|c|c|c|}
\hline Characteristic & $\begin{array}{l}\text { Glycopyrronium } \\
(N=1859)\end{array}$ & $\begin{array}{l}\text { Tiotropium } \\
(N=1077)\end{array}$ \\
\hline Male $(n ; \%)$ & $1379(74.18)$ & 775 (71.96) \\
\hline Age (years; SD) & $63.9(8.92)$ & $63.7(8.40)$ \\
\hline $\mathrm{BMI}\left(\mathrm{kg} / \mathrm{m}^{2} ; \mathrm{SD}\right)$ & $26.5(5.96)$ & $26.6(5.76)$ \\
\hline \multicolumn{3}{|l|}{ Smoking status } \\
\hline Ex-smoker $(n ; \%)$ & $1105(59.44)$ & $621(57.66)$ \\
\hline Current smoker $(n ; \%)$ & $754(40.56)$ & $455(42.29)$ \\
\hline $\begin{array}{l}\text { Duration of COPD, years } \\
\text { (SD) }\end{array}$ & $6.5(5.93)$ & $6.5(5.73)$ \\
\hline $\begin{array}{l}\text { Exacerbation in previous } \\
12 \text { months }(n ; \%)\end{array}$ & $449(24.15)$ & $272(25.26)$ \\
\hline \multicolumn{3}{|c|}{ Concomitant COPD medication $(n ; \%)$} \\
\hline $\begin{array}{l}\text { Short-acting } \\
\text { anticholinergic }\end{array}$ & $576(30.98)$ & $357(33.15)$ \\
\hline $\begin{array}{l}\text { Long-acting } \\
\text { anticholinergic }\end{array}$ & $180(9.68)$ & $97(9.01)$ \\
\hline Short-acting beta-agonist & $268(14.42)$ & $186(17.27)$ \\
\hline Long-acting beta-agonist & $760(40.88)$ & $483(44.85)$ \\
\hline Inhaled corticosteroids & $1015(54.60)$ & $594(55.15)$ \\
\hline Combination LABA/ICS & $647(34.80)$ & $422(39.18)$ \\
\hline Combination LABA/LAMA & $180(9.68)$ & $109(10.12)$ \\
\hline Xanthine & $167(8.98)$ & $91(8.45)$ \\
\hline SGRQ total score (SD) & $48.0(17.66)$ & $48.2(17.49)$ \\
\hline $\mathrm{BDI}$ total score $(\mathrm{SD})$ & $6.2(2.17)$ & $6.3(2.06)$ \\
\hline \multicolumn{3}{|c|}{ Severity of airflow limitation $(n ; \%)$} \\
\hline GOLD 1 (mild) & $2(0.11)$ & $1(0.09)$ \\
\hline GOLD 2 (moderate) & $1148(61.75)$ & $661(61.37)$ \\
\hline GOLD 3 (severe) & $701(37.71)$ & $414(38.44)$ \\
\hline GOLD 4 (very severe) & $8(0.43)$ & $0(0.00)$ \\
\hline \multicolumn{3}{|l|}{ Comorbidities $(n ; \%)$} \\
\hline $\begin{array}{l}\text { Coronary artery bypass } \\
\text { graft }\end{array}$ & $10(0.54)$ & $5(0.46)$ \\
\hline Myocardial infarction & $29(1.56)$ & $32(2.97)$ \\
\hline Stroke & $21(1.13)$ & $14(1.30)$ \\
\hline History of hypertension & $352(18.93)$ & 366 (33.98) \\
\hline Type 2 Diabetes mellitus & $93(5.00)$ & $86(7.99)$ \\
\hline \multicolumn{3}{|l|}{$\mathrm{FEV}_{1}, \mathrm{~L}(\mathrm{SD})$} \\
\hline Pre-bronchodilator & $1.3(0.47)$ & $1.3(0.48)$ \\
\hline Post-bronchodilator & $1.5(0.49)$ & $1.5(0.49)$ \\
\hline \multicolumn{3}{|l|}{$\mathrm{FEV}_{1}, \%$ Predicted (SD) } \\
\hline Pre-bronchodilator & $48.0(13.44)$ & $47.3(13.45)$ \\
\hline Post-bronchodilator & $54.9(13.14)$ & $55.0(13.14)$ \\
\hline \multicolumn{3}{|l|}{ FVC, L (SD) } \\
\hline Pre-bronchodilator & $2.8(0.83)$ & $2.8(0.82)$ \\
\hline Post-bronchodilator & $3.1(0.89)$ & $3.1(0.85)$ \\
\hline \multicolumn{3}{|l|}{$\mathrm{FEV}_{1} / \mathrm{FVC}, \%(\mathrm{SD})$} \\
\hline Pre-bronchodilator & $48.1(10.89)$ & $47.4(10.89)$ \\
\hline Post-bronchodilator & $49.2(10.63)$ & $48.9(10.69)$ \\
\hline $\mathrm{FEV}_{1}$, Reversibility (\%; SD) & $16.7(15.46)$ & $18.6(15.80)$ \\
\hline FVC, Reversibility (\%; SD) & $13.6(14.45)$ & $14.8(15.56)$ \\
\hline $\begin{array}{l}\text { Blood eosinophil count } \\
\text { (cells/ } / \mathrm{L} \text { ) (SD) }\end{array}$ & $2.7(1.84)$ & $2.7(1.76)$ \\
\hline
\end{tabular}

Data are mean (SD) or $\mathrm{n}(\%)$ unless otherwise stated

$B D I$ baseline dyspnea index, $B M I$ body mass index, COPD chronic obstructive pulmonary disease, $F E V_{1}$ forced expiratory volume in 1 second, FVC forced vital capacity, GOLD Global Initiative for Chronic Obstructive Lung Disease, ICS inhaled corticosteroid, LABA long-acting beta-agonist, $\angle A M A$ long-acting muscarinic agonist, o.d. once daily, $S D$ standard deviation, SGRQ St George's Respiratory Questionnaire 
been receiving glycopyrronium compared with tiotropium respectively. Similar non-significance was also observed for these parameters at the time of sustained CID (Table 3).

Table 2. Number of patients with first and sustained clinically important deteriorations in the glycopyrronium and tiotropium treatment groups

\begin{tabular}{llll}
\hline Deterioration & $\begin{array}{l}\text { Glycopyrronium } \\
(N=1859)\end{array}$ & $\begin{array}{l}\text { Tiotropium } \\
(N=1077)\end{array}$ & $P$ value \\
\hline First CID & $1117(60.1)$ & $622(57.8)$ & 0.4658 \\
FEV $_{1}$ & $715(38.5)$ & $404(37.5)$ & 0.4850 \\
SGRQ & $432(23.2)$ & $249(23.1)$ & 0.1658 \\
Exacerbation & $390(21.0)$ & $194(18.0)$ & 0.1735 \\
Sustained CID & $996(53.6)$ & $541(50.2)$ & 0.9765 \\
FEV & $531(28.6)$ & $296(27.5)$ & 0.5764 \\
SGRQ & $104(5.6)$ & $64(5.9)$ & 0.4702 \\
Exacerbation & $390(21.0)$ & $194(18.0)$ & 0.1735 \\
\hline
\end{tabular}

Values are expressed as $n(\%)$

$C I D$ clinically important deteriorations, $F E V_{1}$ forced expiratory volume in

1 second, SGRQ St. George's Respiratory Questionnaire

\section{DISCUSSION}

This post-hoc analysis compared the effect of once-daily glycopyrronium with tiotropium on the delay or reduction in the time to first CID and sustained CID in patients with COPD. The results of this analysis demonstrated that the proportions of patients who experienced either a CID or sustained CID were comparable between patients treated with glycopyrronium and tiotropium, and that the risk of experiencing a CID or sustained CID was significantly reduced with glycopyrronium therapy compared with placebo. Subgroup analysis further supported these results.

In this study, a CID was defined as one or more of the following over the 12-week study period: $a \geq 100 \mathrm{~mL}$ decrease from baseline in pre-dose $\mathrm{FEV}_{1}, \mathrm{a} \geq 4$ point increase in SGRQ total score from baseline and/or a moderate-to-severe COPD exacerbation occurring after the first dose of the study medication. A sustained CID was defined as the occurrence of a CID on $\geq 2$ consecutive study visits 4 weeks apart, or for $\geq 50 \%$ of all subsequent study visits. Of note, the majority of CIDs reported in this study relate to a decrease in lung function. The clinical relevance of a CID or, perhaps more importantly a sustained CID, on the progression or burden of COPD remains to be elucidated, but it is likely that the long-term consequences of these events are under-appreciated at present. ${ }^{15}$ Although supporting data is currently lacking, it is possible that the use of a composite index such as CID or sustained CID may be more sensitive for detection of response to

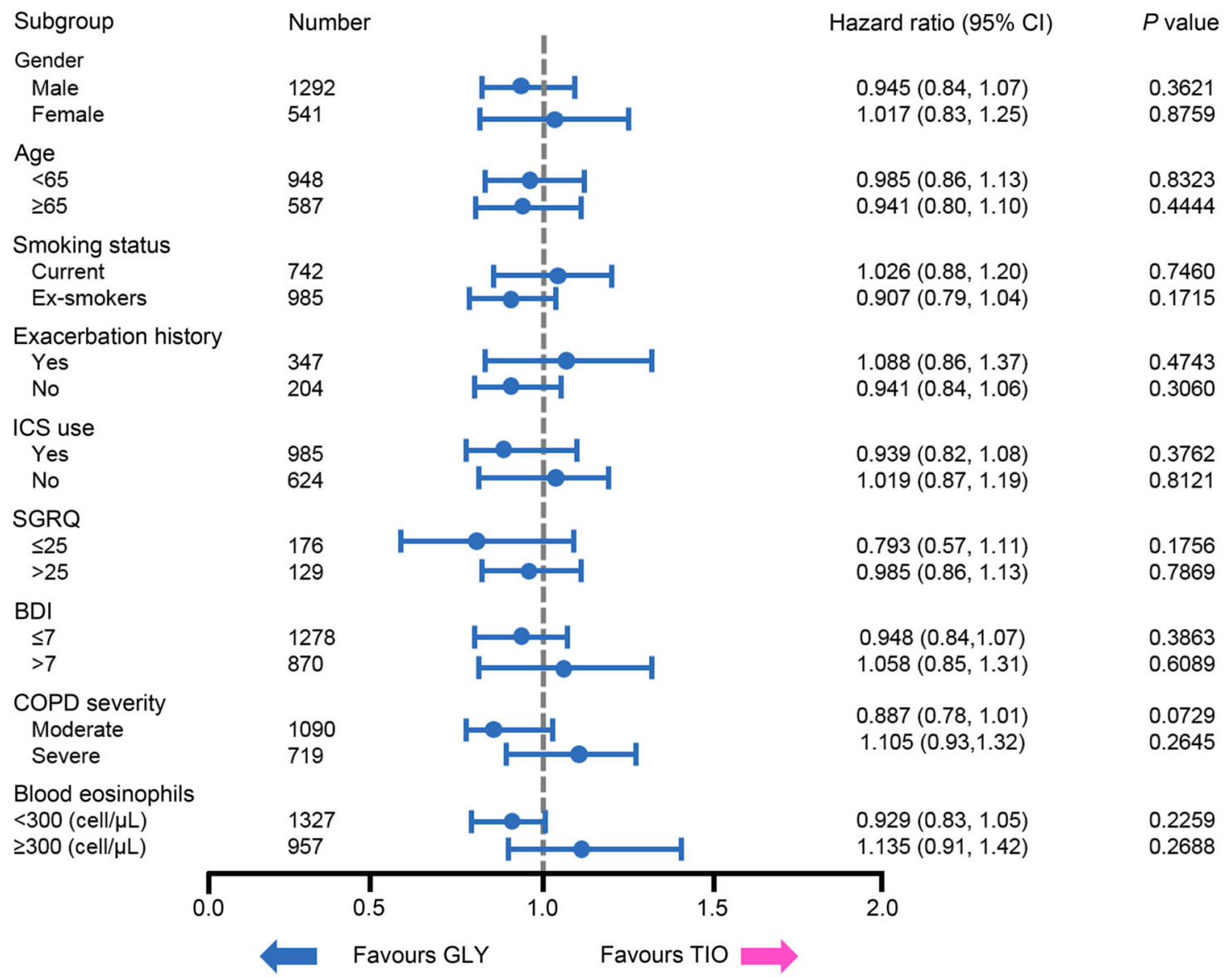

Fig. 1 Clinically important deteriorations (CID): glycopyrronium versus tiotropium subgroup analysis. Forest plot depicting the results of a subgroup analysis which assessed the risk of experiencing a clinically important deterioration with glycopyrronium (GLY; $n=1859)$ treatment compared with tiotropium (TIO; $n=1077$ ), based on gender, age, smoking status, exacerbation history, inhaled corticosteroid (ICS) use, baseline St. George's Respiratory Questionnaire (SGRQ), Baseline Dyspnea Index (BDI) score, COPD severity or blood eosinophil levels. Hazard ratios $\pm 95 \%$ confidence intervals $(\mathrm{Cl})$ are shown 


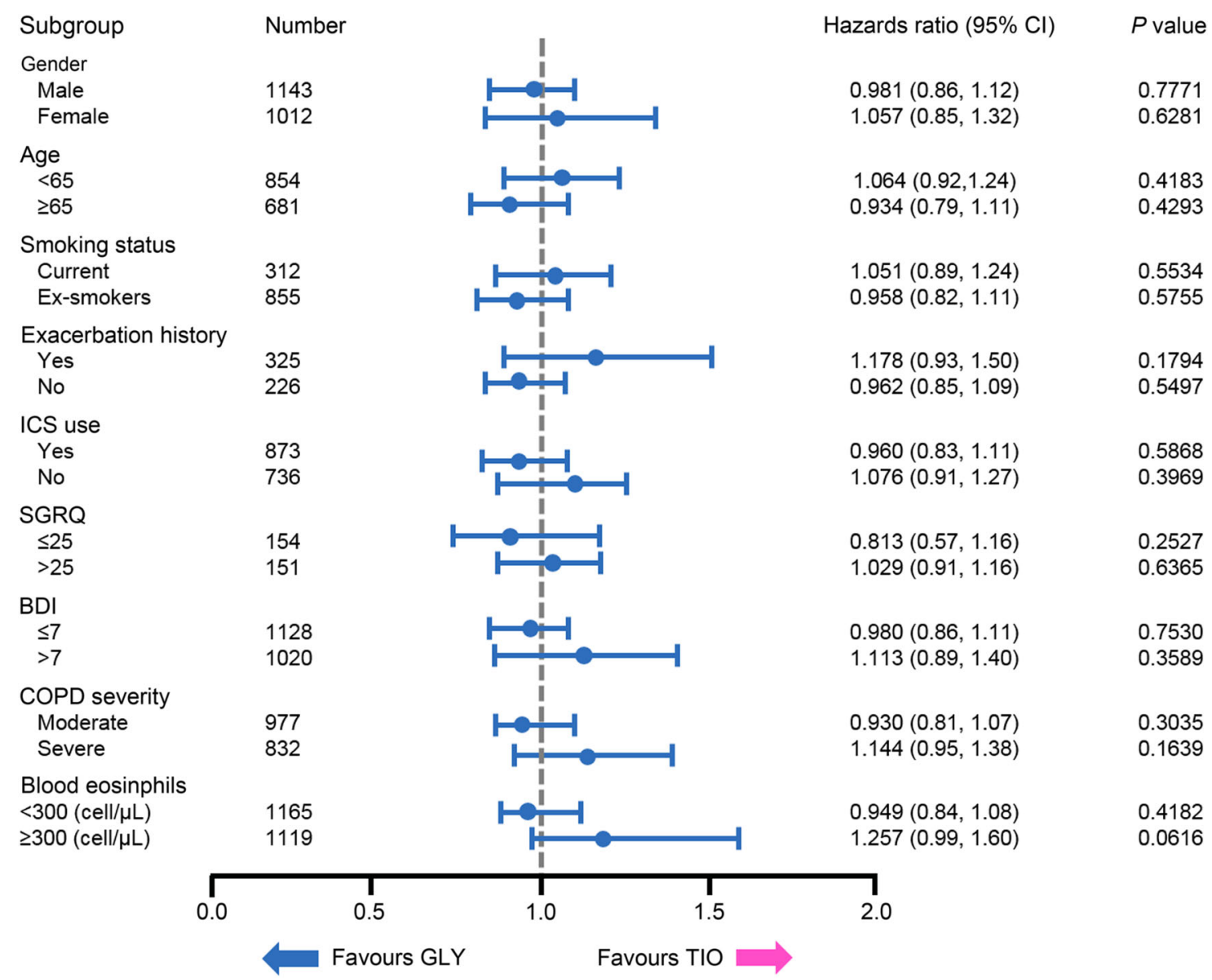

Fig. 2 Sustained clinically important deteriorations: glycopyrronium versus tiotropium subgroup analysis. Forest plot depicting the results of a subgroup analysis which assessed the risk of experiencing a sustained clinically important deterioration with glycopyrronium (GLY; $n=1859$ ) treatment compared with tiotropium (TIO; $n=1077$ ), based on gender, age, smoking status, exacerbation history, inhaled corticosteroid (ICS) use, baseline St. George's Respiratory Questionnaire (SGRQ), Baseline Dyspnea Index (BDI) score, COPD severity or blood eosinophil levels. Hazard ratios $\pm 95 \%$ confidence intervals $(\mathrm{Cl})$ are shown

treatment, compared with a single measured outcome such as $\mathrm{FEV}_{1}{ }^{16}$

Glycopyrronium is a LAMA that has been shown to provide rapid and sustained improvements in lung function, symptoms and health status in patients with moderate-to-severe COPD. ${ }^{7-11}$ Previous studies evaluating the efficacy of glycopyrronium versus tiotropium have demonstrated comparable efficacy with respect to improvements in spirometric endpoints (with the exception of faster onset of action in favor of glycopyrronium), TDI focal score and SGRQ total score. ${ }^{7,9,11}$ The duration of action of once-daily glycopyrronium $(50 \mu \mathrm{g})$ and tiotropium $(18 \mu \mathrm{g})$ has been shown to be comparable. In the GLOW5 study, once-daily glycopyrronium was shown to be equally as effective as tiotropium at maintaining $\mathrm{FEV}_{1} 24 \mathrm{~h}$ post-dose. ${ }^{9}$ Furthermore, data from the GLOW2 study demonstrated similar comparability between glycopyrronium and tiotropium for post-dose $\mathrm{FEV}_{1} \mathrm{AUC}_{0-24 \mathrm{~h}}$ at Week 12 of the study. ${ }^{11}$

The CAT was not available in the analyzed studies, and instead the SGRQ was used to provide the health status/health-related quality-of-life measurements. SGRQ scores have been shown to be reproducible and sensitive to treatment effects over extended time periods, ${ }^{4,17}$ and correlate well with CAT scores $(r=0.84){ }^{18}$ BDI and TDI were initially developed to help to address the limitations associated with mMRC. These indices provide a multidimensional and comprehensive assessment of breathlessness and are helpful in the evaluation of impact of therapies. ${ }^{19,20}$ Of note, glycopyrronium and tiotropium were comparable in terms of their impact on health status, and their impact on CID or sustained CID was unaffected by BDI ( $\leq 7$ or $>7$ ).

Some limitations of this current analysis should be considered when interpreting the results. Although the studies included in this pooled analysis included similar populations and were of similar design, the study durations varied between 12 and 52 weeks. Data from the GLOW5 study were captured at Week 12 , which may not have been sufficiently adequate to observe notable changes in lung function or symptom-related outcomes. In addition, exacerbation burden was shown to be low in the overall population, which precluded our ability to conduct a meaningful risk calculation. Although similar definitions of a CID as described herein have been employed previously, ${ }^{15,16,21}$ the fact that any strong correlation between $a$ CID and other wellestablished markers of disease progression (e.g., $\mathrm{FEV}_{1}$ decline) is yet to be demonstrated, is a potential limitation in this study. Furthermore, the data presented in this post-hoc analysis were collected from four individual clinical trials which were not originally designed to assess CID.

Taken together, the results of this post-hoc analysis demonstrate that glycopyrronium is effective in delaying/reducing time to CIDs, with similar efficacy to tiotropium. This is an important consideration as over half of the patients studied in this analysis experienced at least one CID. Current COPD guidelines recommend that health status and exacerbation history should be considered in disease assessment. ${ }^{5}$ CIDs encompassing these parameters can provide new insight into the management of 
a

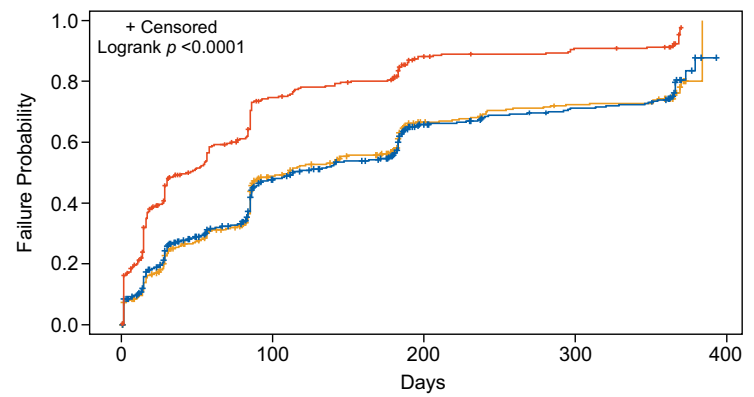

$\begin{array}{rccccc}\text { Glycopyrronium } & 1859 & 767 & 168 & 149 & 0 \\ \text { Placebo } & 760 & 175 & 31 & 22 & 0 \\ \text { Tiotropium } & 1077 & 379 & 88 & 70 & 0\end{array}$

b

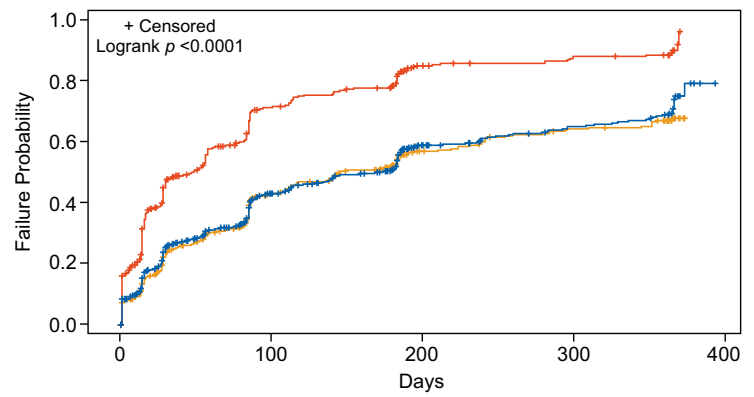

_ Gly _— Placebo — Tio

Glycopyrronium 1859

Placebo 760

Tiotropium 1077

199

154

192

34
97

154
24
70

Fig. 3 Kaplan-Meier time to clinically important deteriorations (CID): glycopyrronium versus tiotropium and placebo. Kaplan-Meier graph depicting the time to $\mathbf{a}$ first or $\mathbf{b}$ sustained CID in patients receiving glycopyrronium (blue line), tiotropium (yellow line), and placebo (orange line)

Table 3. Comparison of FEV 1 and SGRQ at baseline and at first and sustained clinically important deterioration between the glycopyrronium and tiotropium treatment groups

\begin{tabular}{llll}
\hline Deterioration & Glycopyrronium & Tiotropium & $P$ value \\
\hline First CID & & & \\
FEV $_{1}$ (L) & $N=715$ & $N=404$ & \\
At baseline & $1.47 \pm 0.481$ & $1.50 \pm 0.527$ & 0.3045 \\
At time of first CID & $1.29 \pm 0.466$ & $1.32 \pm 0.501$ & 0.3452 \\
SGRQ (Units) & $N=432$ & $N=249$ & \\
At baseline & $43.42 \pm 16.791$ & $43.33 \pm 16.928$ & 0.9497 \\
At time of first CID & $53.92 \pm 16.87$ & $57.74 \pm 17.47$ & 0.3903 \\
Sustained CID & & & \\
FEV (L) & $N=531$ & $N=296$ & \\
At baseline & $1.50 \pm 0.482$ & $1.51 \pm 0.534$ & 0.7356 \\
At time of sustained CID & $1.33 \pm 0.480$ & $1.33 \pm 0.499$ & 0.9184 \\
SGRQ (Units) & $N=104$ & $N=64$ & \\
At baseline & $43.09 \pm 16.914$ & $43.11 \pm 18.328$ & 0.9947 \\
At time of sustained CID & $54.02 \pm 17.5$ & $52.36 \pm 18.18$ & 0.5617 \\
\hline
\end{tabular}

Data are presented as mean \pm standard deviation

$F E V_{1}$ forced expiratory volume in 1 second, SGRQ St George's Respiratory Questionnaire, CID clinically important deterioration, $N$ number of patients

COPD, which might help reduce disease progression and individualize patient care particularly with regards to lung function, health status and exacerbations. Further studies, with a larger population size and longer follow-up, will be required to confirm these findings. The long-term impact of CID on COPD disease progression also remains to be studied. Finally, the results presented here suggest that glycopyrronium may be an alternative LAMA option for patients with COPD.

\section{METHODS}

This post-hoc analysis was carried out using lung function, health status, and exacerbation data from 2936 patients in four large, multicenter, randomized clinical trials conducted in patients with moderate-to-severe airflow obstruction, namely the GLOW1, GLOW2, GLOW5 $5^{9-11}$ and SHINE studies, ${ }^{7}$ which had similar study populations (Supplementary Table 1). These studies were registered with clinical trials.gov as NCT01005901, NCT00929110, NCT01613326 and NCT01202188 respectively. A fifth study, the SPARK study, also compared glycopyrronium with tiotropium for lung function, health status and exacerbation outcomes. ${ }^{22}$ However, as SPARK was conducted in a different COPD patient population (patients with severe to very severe airflow obstruction), it was decided not to include data from SPARK in this analysis. All available data (captured at the end of each respective study) were included. The exacerbation data used within this post-hoc analysis were captured at the time at which the exacerbation occurred during the entire duration of the studies. GLOW5 was a 12-week study; the $\mathrm{FEV}_{1}$, and SGRQ data were captured from this study every 4 weeks up to Week 12. GLOW1 and SHINE were both 26-week studies, and the data from these studies were collected every 4 weeks up to week 26. Lastly, the GLOW2 study was conducted over a 52-week period, and the $\mathrm{FEV}_{1}$, and SGRQ data were collected from this study every 4 weeks up to Week 52.

Patients

Inclusion criteria were age $\geq 40$ years with a smoking history of $\geq 10$ packyears and moderate-to-severe stable COPD [defined as postbronchodilator $\mathrm{FEV}_{1} \geq 30-<80 \%$ predicted, and post-bronchodilator $\mathrm{FEV}_{1} /$ forced vital capacity (FVC) ratio $<0.70]$.

\section{Clinically important deterioration}

The primary endpoint of this study was the delay and/or reduction in occurrence of CIDs with once-daily glycopyrronium $50 \mu \mathrm{g}$ (delivered via the Breezhaler device; $N=1859)$ compared with once-daily tiotropium $18 \mu \mathrm{g}$ (delivered via the HandiHaler device; $N=1077$ ) in the GLOW1, GLOW2, GLOW5 and SHINE studies. Tiotropium was prescribed as openlabel in GLOW2 and SHINE. Secondary endpoints included evaluation of breathlessness measured using the TDI and health status according to the SGRQ. The duration of the four individual studies included in this analysis ranged from 12 to 52 weeks, and all available data were included in the analyses.

CID was defined as $\geq 1$ of the following components at the post-baseline visit:

- a $100 \mathrm{~mL}$ decrease from baseline in pre-dose $\mathrm{FEV}_{1}{ }^{13,23}$

- $\geq 4$ point increase in SGRQ total score from baseline ${ }^{14}$

- a moderate-to-severe COPD exacerbation occurring after the first dose of the study medication ${ }^{15}$

Time to CID was the time to the first event of any of the above three components. A sustained CID for this analysis was defined as a CID occurring on two or more consecutive visits 4 weeks apart or for $\geq 50 \%$ of all available subsequent visits. ${ }^{24}$ COPD exacerbations were defined as worsening of two or more major symptoms (dyspnea, sputum volume or sputum purulence) for at least two consecutive days or worsening of any one major symptom together with any minor symptom (colds, fever without other cause, increased cough, increased wheeze or sore throat) for at least two consecutive days. ${ }^{9}$

The GOLD strategy recommends the use of the CAT or mMRC dyspnea scale for classifying patients into the "low-symptom" or "high-symptom" groups. ${ }^{5}$ As these measures were not employed in the GLOW or SHINE studies, SGRQ total score and BDI were used as surrogate measures for health status and breathlessness respectively, in addition to baseline lung function ( $\mathrm{FEV}_{1}<50 \%$ and $\geq 50 \%$ ).

The SGRQ is designed to measure impact on overall health, daily life, and perceived well-being in patients with obstructive airways disease and has become the most widely documented measure of health status in COPD trials. ${ }^{5,25}$ Scores range from 0 to 100 , with higher scores indicating more limitations. ${ }^{25}$ Earlier studies have demonstrated that SGRQ and CAT scores 
are closely correlated, ${ }^{26-28}$ with a CAT score of 10 being comparable to a SGRQ total score of $\geq 25 .^{5,26}$ As CAT scores were not reported in the GLOW or SHINE glycopyrronium studies, it was not included in the current analysis. The BDI has previously been shown to correlate with mMRC grading for dyspnea assessment. ${ }^{20,29-32}$ BDI cut-off scores of $\geq 7$ and $<7$ were used in the subgroup analyses of this study as a surrogate for mMRC grades $0-1$ and $\geq 2$, respectively. The cut-off value of 7 was chosen since this is the median of the 13-point BDI scale and similar cut-off values were used in another post-hoc analysis of pooled data from trials where BDI was used as a surrogate for mMRC. ${ }^{33}$

\section{Statistical analyses}

All available patients in the full analysis set (FAS) were included in this pooled analysis, and their data were captured at the end of their respective studies (12 to 52 weeks) for use in this analysis. As this was a post-hoc analysis, no power or sample size justification was considered.

These analyses assessed the effect of glycopyrronium versus tiotropium, and glycopyrronium versus placebo on significant delay and/or reduction in the occurrence of CID and sustained CID. The significance level of twosided 0.05 was used to evaluate the statistical significance of treatment comparisons, and the significant impact of the covariates on the time to CID and sustained CID. Data analysis was performed using SAS software Version 9.13. Due to the large sample size (2936 patients), the normality assumption of the data was deemed sufficient to be analyzed by ANCOVA/ mixed effect model.

The summary statistics ( $N$ number and percentage) of CIDs are included, and the Kaplan-Meier Curves with log rank tests are presented for pooled glycopyrronium versus tiotropium, and versus placebo, results. The median times with $95 \%$ confidence intervals, (25\% and $75 \%$ quartiles) of the time to event are presented. The Cox proportional hazard model was used, with treatment group, gender, age group, baseline COPD severity, smoking status (Yes/No), and high $(\geq 300)$ or low $(<300)$ baseline eosinophil status, as treatment comparisons.

If a patient did not meet the criteria for a deterioration during the study, the patient was censored at the end of the study for the time to event analysis. Patients who had no event or discontinued early from the study, were censored from the analysis at the last contact date of the study.

The subgroups defined below were used in the subgroup analyses of the time to CID or sustained CID:

- Male versus female

- (GOLD A and B) and (GOLD C and D) $)^{34}$ at baseline

- Low and high BDI: $\leq 7$ and $>7$

- Low and high SGRQ: $\leq 25$ and $>25$

- Age $<65$ and $\geq 65$ years at baseline

- Ex-versus current smokers at baseline

- Subjects classified as high $(\geq 300)$ or low $(<300)$ eosinophils at baseline

- ICS use at baseline (Yes/No)

- History of any exacerbation in previous year before randomization (Yes/No)

\section{Code availability}

Any codes used in the analyses of these data are available from the authors.

\section{Data availability}

The current post-hoc analyses were performed based on primary data from four studies. These primary data have been published previously, ${ }^{7,9-11}$ and result summaries have been posted on the Novartis clinical trial database (https://www.novartisclinicaltrials.com/TrialConnectWeb/home.nov) and other online public databases. Given the post-hoc nature of the data discussed in the present manuscript, these have not been made available on any publicly-accessible database. More information on Novartis' position on access to clinical trial results and patient-level data is available here: https://www.novartis.com/our-science/clinical-trials/clinical-trialinformation-disclosure.

\section{Ethical approval}

These studies were individually approved by the relevant ethics committee and institutional review board at the participating centers at the time of their undertaking. The current post-hoc analysis used anonymized data from these studies, and hence ethics committee or institutional review board approvals were not necessary.

\section{Informed consent}

All participants provided written informed consent to take part in the GLOW1, GLOW2, GLOW5 and SHINE studies.

\section{ACKNOWLEDGEMENTS}

The authors thank Clarice Field $\mathrm{PhD}$ and Gillian Lavelle PhD of Novartis for providing medical writing support which was funded by Novartis AG, Basel, Switzerland in accordance with Good Publication Practice (GPP3) guidelines (http://www.ismpp.org/gpp3). This analysis was funded by Novartis AG, Basel, Switzerland. None of the authors received any compensation related to the development of this manuscript.

\section{AUTHOR CONTRIBUTIONS}

A.D'U., G.B., S.S., P.G., and P.A. made substantial contributions to the conception or design of the work or the acquisition, analysis, or interpretation of the data. All authors participated in the drafting of the work, revised it critically for important intellectual content, and gave final approval of the completed version. All authors agree to be accountable for all aspects of the work in ensuring that questions related to the accuracy or integrity of any part of the work are appropriately investigated and resolved.

\section{ADDITIONAL INFORMATION}

Supplementary information accompanies the paper on the npj Primary Care Respiratory Medicine website (https://doi.org/10.1038/s41533-018-0084-8).

Competing interests: A.D'U. has received research, consulting and lecturing fees from GlaxoSmithkline, Sepracor, Schering Plough, Altana, Methapharma, AstraZeneca, ONO pharma, Novartis, KOS Pharmaceuticals, Almirall SA and Forest Laboratories. A.D'U. is also an Associate Editor of npj Primary Care Respiratory Medicine. P.A. is a full-time employee of Novartis Pharmaceutical Co. P.G., G.B. and S.S. are full-time employees of Novartis Pharma AG.

Publisher's note: Springer Nature remains neutral with regard to jurisdictional claims in published maps and institutional affiliations.

\section{REFERENCES}

1. Han, M. K. et al. Chronic obstructive pulmonary disease phenotypes: the future of COPD. Am. J. Respir. Crit. Care Med. 182, 598-604 (2010).

2. Rennard, S. I. COPD heterogeneity: what this will mean in practice. Respir. Care 56, 1181-1187 (2011).

3. Agusti, A. et al. Characterisation of COPD heterogeneity in the ECLIPSE cohort. Respir. Res. 11, 122 (2010).

4. Jones, P., Miravitlles, M., van der Molen, T. \& Kulich, K. Beyond FEV(1) in COPD: a review of patient-reported outcomes and their measurement. Int. J. Chron. Obstruct. Pulmon. Dis. 7, 697-709 (2012).

5. Martin, A. L. et al. The association of lung function and St. George's respiratory questionnaire with exacerbations in COPD: a systematic literature review and regression analysis. Respir. Res. 17, 40 (2016).

6. King, P. T. Inflammation in chronic obstructive pulmonary disease and its role in cardiovascular disease and lung cancer. Clin. Transl. Med. 4, 68 (2015).

7. Bateman, E. D. et al. Dual bronchodilation with QVA149 versus single bronchodilator therapy: the SHINE study. Eur. Respir. J. 42, 1484-1494 (2013).

8. Beeh, K. M., Singh, D., Di Scala, L. \& Drollmann, A. Once-daily NVA237 improves exercise tolerance from the first dose in patients with COPD: the GLOW3 trial. Int. J. Chron. Obstruct. Pulmon. Dis. 7, 503-513 (2012).

9. Chapman, K. R. et al. A blinded evaluation of the efficacy and safety of glycopyrronium, a once-daily long-acting muscarinic antagonist, versus tiotropium, in patients with COPD: the GLOW5 study. Bmc. Pulm. Med. 14, 4 (2014).

10. D'Urzo, A. et al. Efficacy and safety of once-daily NVA237 in patients with moderate-to-severe COPD: the GLOW1 trial. Respir. Res. 12, 156 (2011).

11. Kerwin, E. et al. Efficacy and safety of NVA237 versus placebo and tiotropium in patients with COPD: the GLOW2 study. Eur. Respir. J. 40, 1106-1114 (2012).

12. D'Urzo, A. D. et al. Safety of inhaled glycopyrronium in patients with COPD: a comprehensive analysis of clinical studies and post-marketing data. Int. J. Chron. Obstruct. Pulmon. Dis. 10, 1599-1612 (2015). 
13. Donohue, J. F. Minimal clinically important differences in COPD lung function. COPD 2, 111-124 (2005).

14. Jones, P. W. St. George's Respiratory Questionnaire: MCID. COPD 2, 75-79 (2005).

15. Singh, D. et al. Prevention of clinically important deteriorations in COPD with umeclidinium/vilanterol. Int. J. Chron. Obstruct. Pulmon. Dis. 11, 1413-1424 (2016).

16. Anzueto, A. R. et al. The effect of indacaterol/glycopyrronium versus tiotropium or salmeterol/fluticasone on the prevention of clinically important deterioration in COPD. Int. J. Chron. Obstruct. Pulmon. Dis. 12, 1325-1337 (2017).

17. Jones, P., Lareau, S. \& Mahler, D. A. Measuring the effects of COPD on the patient. Respir. Med. 99, S11-S18 (2005).

18. Jones, P. W. et al. Properties of the COPD assessment test in a cross-sectional European study. Eur. Respir. J. 38, 29-35 (2011).

19. Mahler, D. A. et al. Validity and responsiveness of the self-administered computerized versions of the baseline and transition dyspnea indexes. Chest 132, 1283-1290 (2007).

20. Mahler, D. A. \& Wells, C. K. Evaluation of clinical methods for rating dyspnea. Chest 93, 580-586 (1988)

21. Singh, D., D'Urzo, A. D., Chuecos, F., Munoz, A. \& Garcia Gil, E. Reduction in clinically important deterioration in chronic obstructive pulmonary disease with aclidinium/formoterol. Respir. Res. 18, 106 (2017).

22. Wedzicha, J. A. et al. Analysis of chronic obstructive pulmonary disease exacerbations with the dual bronchodilator QVA149 compared with glycopyrronium and tiotropium (SPARK): a randomised, double-blind, parallel-group study. Lancet Respir. Med. 1, 199-209 (2013).

23. Westwood, M. et al. Relationship between FEV1 change and patient-reported outcomes in randomised trials of inhaled bronchodilators for stable COPD: a systematic review. Respir. Res. 12, 40 (2011).

24. Jones, P. W., Quirk, F. H., Baveystock, C. M. \& Littlejohns, P. A self-complete measure of health status for chronic airflow limitation. The St. George's Respiratory Questionnaire. Am. Rev. Respir. Dis. 145, 1321-1327 (1992).

25. Jones, P. W., Quirk, F. H. \& Baveystock, C. M. The St George's Respiratory Questionnaire. Respir. Med. 85, 25-31 (1991).

26. Han, M. K. et al. GOLD 2011 disease severity classification in COPDGene: a prospective cohort study. Lancet Respir. Med. 1, 43-50 (2013).
27. Jones, P. W., Adamek, L., Nadeau, G. \& Banik, N. Comparisons of health status scores with MRC grades in COPD: implications for the GOLD 2011 classification. Eur. Respir. J. 42, 647-654 (2013).

28. Ringbaek, T., Martinez, G. \& Lange, P. A comparison of the assessment of quality of life with CAT, CCQ, and SGRQ in COPD patients participating in pulmonary rehabilitation. COPD 9, 12-15 (2012).

29. Camargo, L. A. \& Pereira, C. A. Dyspnea in COPD: beyond the modified Medical Research Council scale. J. Bras. Pneumol. 36, 571-578 (2010).

30. Chhabra, S. K., Gupta, A. K. \& Khuma, M. Z. Evaluation of three scales of dyspnea in chronic obstructive pulmonary disease. Ann. Thorac. Med. 4, 128-132 (2009).

31. Mahler, D. A. et al. Patient-reported dyspnea in COPD reliability and association with stage of disease. Chest 136, 1473-1479 (2009).

32. Perez, T. et al. Modified Medical Research Council scale vs Baseline Dyspnea Index to evaluate dyspnea in chronic obstructive pulmonary disease. Int. J. Chron. Obstruct. Pulmon. Dis. 10, 1663-1672 (2015).

33. Mahler, D. A. et al. Indacaterol vs tiotropium in COPD patients classified as GOLD A and B. Respir. Med. 109, 1031-1039 (2015).

34. Global Initiative for Chronic Obstructive Lung Disease (GOLD). Global Strategy for the Diagnosis, Management and Prevention of Chronic Obstructive Pulmonary Disease http://goldcopd.org/ (2015).

(i) Open Access This article is licensed under a Creative Commons Attribution 4.0 International License, which permits use, sharing adaptation, distribution and reproduction in any medium or format, as long as you give appropriate credit to the original author(s) and the source, provide a link to the Creative Commons license, and indicate if changes were made. The images or other third party material in this article are included in the article's Creative Commons license, unless indicated otherwise in a credit line to the material. If material is not included in the article's Creative Commons license and your intended use is not permitted by statutory regulation or exceeds the permitted use, you will need to obtain permission directly from the copyright holder. To view a copy of this license, visit http://creativecommons. org/licenses/by/4.0/.

(c) The Author(s) 2018 